\title{
Will Iran achieve the SDG 3.4 at national and sub- national levels?
}

\author{
Ali Akbar Haghdoost \\ Kerman University of Medical Sciences \\ Farshad Farzadfar \\ Tehran University of Medical Sciences \\ Moein Yoosefi \\ Tehran University of Medical Sciences \\ Kamyar Mansori \\ Zanjan University of Medical Sciences \\ Bagher Larijani \\ Tehran University of Medical Sciences \\ Mohammad Reza Baneshi \\ Kerman University of Medical Sciences \\ Fatemeh Khosravi Shadmani ( $\sim$ khosravishadman@gmail.com ) \\ Kermanshah University of Medical Sciences
}

\section{Research Article}

Keywords: Sustainable development goals, Non- communicable diseases, Risk factor, projection, Iran

Posted Date: May 5th, 2021

DOI: https://doi.org/10.21203/rs.3.rs-479910/v1

License: (c) (i) This work is licensed under a Creative Commons Attribution 4.0 International License. Read Full License 


\section{Abstract}

In this study, different scenarios have been used to project Iran's chance to achieve SDG 3.4. Unconditional Probability of Dying (UPOD) through the Bayesian model averaging for four major categories of NCDs was projected on the basis of Death Registry System data at the national and sub-national levels. The prevalence of the risk factors was projected by 2030 based on STEPs data and additional studies. Assuming that the global reduction in risk factors proposed by WHO is performed in Iran, UPOD was projected again and then the possibility of achieving the target was estimated. If the current trend continues, the UPOD will be reduced from $17.5 \%$ (95\% Ul: 16.3-19.2) in 2010 and $14.7 \%$ (13.3-16.2) in 2015 to $10.8 \%$ (7.9-14.3) in 2030. If the risk factors are reduced to the global target level, 68236 deaths in 2010 and 54418 deaths in 2015 baselines will be avoided. By 2030, the UPOD after subtracting the avoidable deaths, will be 5.44 (3.51-7.39) in 2010 and 6.55 (5.00-8.13) in 2015 baselines. This way some provinces will meet SDG 3.4. If the current trend continues, Iran will and will not achieve the SDG 3.4 in 2010 and 2015 baselines, respectively. However, if the global target set for reducing risk factors is achieved, Iran will meet all expectations in SDG 3.4 except in Asthma and COPD. Therefore, effective interventions are recommended to be designed and followed to reduce Asthma and COPD.

\section{Introduction}

All countries in the world are committed to achieve Sustainable Development Goals (SDGs) introduced by the United Nations (UN) in September 2015 ${ }^{1}$. The forth target of the third SDGs (SDG 3.4) is focused on Non-Communicable Diseases (NCDs). This target is expected to make a one-third drop in the Unconditional Probability of Dying (UPoD) from NCDs in 30-70 year age group by $2030{ }^{1}$. Also, World Health Organization (WHO) has developed a global monitoring framework for NCDs along with a set of targets for modifiable risk factors to tackle the global epidemic of NCDs ${ }^{2}$. Bringing these measures into account is necessary to meet SDGs in many countries.

Iran is experiencing epidemiological transition. As a result of these epidemiological changes, non-communicable diseases have become the greatest public health problem in the country ${ }^{3}$. It will lead to years of life lost from premature deaths that, by the same token, will have a great impact on life expectancy, development, and economics ${ }^{4}$.However, we do not have accurate data on current and future trends of Unconditional Probability of Dying from NCDs in national and provincial levels to trace the progress of achieving SDG 3.4. Also, trends for UPoD can be varying by variation of a single risk factor or joint effect of the risk factors. Therefore, to achieve the SDG 3.4, evidence based planning should be carried out. Plus, avoidable number of deaths, resulted from reduction of the risk factors to the degree pinned down by WHO, and its impact on UPOD should be modeled and estimated. Given the limited resources, realizing the priorities is imperative for the policy maker because cost-effective intervention should be designed based on the existing resources.

The aim of this study is to project Iran's achievement status to SDG 3.4 through the different scenarios. These scenarios are based on a reduction of the risk factors to the target levels set by WHO. So far, no study has been conducted on this issue in Iran and only few similar studies are performed in the world. This paper also studies the degree to which SDG 3.4 will be achieved at national and sub-national levels by sex. The results can be employed for planning and evidence based policy-making at national and sub-national levels In Iran.

\section{Results}

\section{Current situation}

Based on our results, if the existing trend goes on, a one-third reduction in UPoD will be achieved by 2030 in scenario10 (if the trend is narrowed down to the categories of NCDs, CVDs and diabetes as separate trends will be very close to reaching target but won't meet the expected levels) whereas, this reduction will not be met in scenario15. The values of UPoD due to cancers were $4.2 \%$ (95\% Ul: 3.8- 4.6) and 3.2 \% (2.9- 3.6) in scenario10 and scenario15 respectively. This value is projected to be $2.2 \%(1.5-3.1)$ by 2030 .

The corresponding values for scenario10, scenario15 and the projected value for 2030 in CVDs are $10.8 \%$ (9.8- 12.0), 9.3 \% (8.3- 10.3.), and 7.0 \% (5.1- 9.3) respectively. The values of UPOD due to asthma and COPD in females were $1.7 \%$ (1.6- 1.8$)$ and $1.5 \%$ (1.4- 1.6$)$ in scenario10 and scenario15 respectively; this value is projected to drop to $1.0(0.8-1.3)$ by 2030 . The corresponding values for diabetes are $0.7 \%(0.6-0.7), 0.6 \%(0.5-0.6)$, and $0.4 \%(0.3-0.6)$ respectively. The trends and projections for UPoD, in the period from 2001 to 2030, are shown in Fig 1a by categories. The trends and projections of UPoD for the years of 2001 to 2030 are indicated in Fig 1 by sex and categories of NCDs.

\section{Prevalence of risk factors}

Based on our projections, the age-standardized prevalence of diabetes, hypertension, obesity and overweight, and physical inactivity from 2015 to 2030 will increase respectively by $17,41,32$ and $29 \%$ in females. The corresponding values will be 20, 41, 48 and $39 \%$ in males. The prevalence of smoking decreased by $27 \%$ in females and $28 \%$ in males in the same period. Also, mean of salt intake will decrease by $12 \%$ and $16 \%$ in females and males, respectively.

The age-standardized prevalence and projection of diabetes, hypertension, obesity and overweight, physical inactivity, smoking, and mean of salt intake are shown in table 2 in three time periods. The prevalence of risk factors were provided at sub-national level in supplementary appendix 3.

\section{Avoidable deaths by 2030}

Based on the projected mortality rate and the prevalence of risk factors in 2030 , avoidable deaths from the risk factors are estimated in three different scenarios. The number of avoidable deaths by sex, cause, and risk factor are shown in table 3 . The number of avoidable deaths at sub-national level is provided in supplementary appendix 4 . The projected number of deaths will be 47,847 in females and 64,784 in males among $30-70$ age group by 2030 . The number of avoidable deaths from joint effects of risk factors in theoretical minimum exposure risk level (TMREL) will be 42,928 in females and 55,578 in

Page $2 / 12$ 
males. The corresponding number in WHO-based scenario are 30,638 and 37,598 in females and males in scenario10. These values are 24,853 and 29,566 in WHO-based scenario among females and males in scenario15.

\section{WHO-based scenario}

If the risk factor targets determined by WHO are met, Iran will meet SDG 3.4 in both WHO-based scenario10 and WHO-based scenario15. Iran, at national level, will achieve the goal for each of the four disease categories in WHO-based scenario10 (Fig 2). However the country will not achieve a one-third reduction in the UPoD due to asthma and COPD in WHO-based scenario15 (Fig 3). The values of UPoD due to cancer, CVDs, Asthma \& COPD and diabetes will be respectively $1.59,2.54,1.07$ and 0.22 in WHO-based scenario10, and 1.60, 3.55, 1.05, and 0.30 in WHO-based scenario15 by 2030 . The increase in life expectancy, after elimination of the number avoidable deaths in WHO based scenario, is shown in table 4.

\section{Subnational}

\section{Current situation}

In scenario10, if the current trend prevails, then, of the total number of 31 provinces, 30 provinces will meet SDG 3.4 among females in cancer by 2030 . Also, by the same time-period, 21 provinces will achieve the targets in CVDs, Asthma and COPD, and diabetes (Fig 4a). Plus, 24 provinces in cancer, 22 provinces in CVDs, 27 provinces in Asthma and COPD and 24 provinces in diabetes will meet SDG 3.4 designed for males (Fig 4b).

On the other hand, in scenario15, by 2030, 21 provinces in cancer, 9 provinces in CVDs, 16 provinces in Asthma and COPD, and 18 provinces in diabetes will reach the target in females (Fig 4c). Moreover, 17 provinces in cancer, 9 provinces in CVDs, 21 provinces in Asthma and COPD, and18 provinces in diabetes will meet SDG 3.4 in males (Fig 4d

\section{WHO-based scenario}

The Joint effect of the risk factors in WHO based scenario has shown that all of the provinces will meet SDG 3.4 in cancer and CVDs; 21 provinces in asthma and COPD and 29 provinces in diabetes will achieve SDG 3.4 designed for females. The corresponding number of provinces are 27 and 30 for males (WHObased scenario10). Also, 30 provinces will reach SDG 3.4 in cancer and CVDs in females; whereas, the number of the provinces meet SDG 3.4 in cancer and CVDs will be 26 and 30 in males respectively. Plus, 15 provinces in asthma and COPD, and 29 province in diabetes will achieve SDG 3.4 in females. On the other hand, 15 ad 29 provinces will reach SDG 3.4 in asthma and COPD and diabetes in males respectively (Fig 5).

\section{Discussion}

The results showed that with continuation of the current trend (adjusted with the prevalence of risk factors), Iran would not achieve SDG 3.4 and in order to achieve a one third drop in UPoD, some interventions should be conducted in scenario15. However, the country will be close to achieving the one third reduction in UPoD (reaching SDG 3.4) in scenario10. If the decrease in prevalence of risk factors was in line with WHO suggestions, SDG 3.4 wouldn't be achieved by reducing just one single risk factor. In WHO-based scenario10 and WHO-based scenario15, estimating the joint effect of risk factors could prevent 60.5 and 48 percent of the projected deaths by 2030, respectively. In WHO-based scenario10, reducing avoidable deaths would result in achieving SDG 3.4 in Iran. However, in WHO-based scenario15, the country would achieve SDG 3.4 in cancer, cardiovascular disease, and diabetes. Therefore, more efforts and serious interventions are needed in terms of asthma and COPD. It worth mentioning that there is considerable diversity among the provinces regarding the achievement of SDG 3.4.

Iran has experienced a downward trend in deaths from non-communicable diseases and this trend will be continued by $2030^{5}$; however, this downward trend is not enough for achieving SDG 3.4. An international study showed that Iran will meet the target by 2030 in scenario 15 at national level ${ }^{6}$. The result of the aforementioned study is not in line with those of our study. The reason behind this inconsistency may be the employed data. In our study, the total of 524174 real data points are used for modeling. These information were divided by province, age, cause, sex in 15 years but results from the mentioned study ${ }^{6}$ are model driven.

Another study showed that, in scenari10, Mexico will not able to achieve SDG 3.4 if the current situation prevails ${ }^{7}$. The mortality rate from non-communicable diseases in Mexico has declined to $22.9 \%$ which it not enough for achieving SDG 3.4. In our study, in scenario10, change percent of UPoD will be -39\% in 2030 . That it, the country will meet the target but the achievement will not be equal in the NCDs categories and provinces. Also, Iran has declined $27 \%$ in UPoD in 2015 baseline.

Another study concluded that if the current trends in risk factors remain stable in China by $2030,13.1 \%$ of premature deaths from NCDs are decreased which will be insufficient for reaching SDG 3.4. In the combined scenario, in which all the risk factor reduction targets are achieved, the mortality from cardiovascular and COPD will be reduced by one third ${ }^{8}$. However, Iran will not meet the target in asthma and COPD category.

The present study was carried out using a huge bulk of integrated datasets, providing (for the first time) a projection for the risk factors. Based on the current trend and targets set by the WHO for risk factors, the present study defined different scenarios and provided the benefits of intervention, or a series of interventions, in light of the reduction in the number of deaths. The present study is one of the first few investigations conducted on the issue. It employs a comprehensive approach with modeling and projection to help policy-making and planning for NCDs.

These results provide a brand new dashboard for decision making and optimal allocation of resources by policy makers in the health system. For projection of UPoD, there were several models; in order to employ all possible models and to avoid missing data, BMA was used for projection of UPoD. Another strength of 
the study is the use of valid RRs extracted from global significant studies; as a result, residual confounding was minimized. All analyses were performed by sex and province. Considering the vast spectrum of this study, there were some limitations; first, the alcohol consumption trend was not available in Iran. Its low prevalence in STEPs data in 2016 (supplement appendix 4), this risk factors were put aside from the study. Sacristy in the data was addressed with various modeling techniques including Sptio-temporal and GPR. Changes in administrative divisions, increasing the number of provinces were addressed by Misalignment approach. Also, Alterations in definitions over the time were modified by Cross Walk method and lack of data on the prevalence of risk factors for the age group of 65-69 years in the STEPs before 2011 were addressed by Fractional Polynomial Models.

According to the projections performed in this study, Iran will face a critical situation in which people involved multiple risk factors for the morbidity and mortality from NCDs. Hypertension, physical inactivity, obesity, and diabetes are on the rise and despite the decreasing trend in mean of salt intake, this risk factor indicates a higher number than the global standard. Therefore, there should be interventions designed and implemented at the individual, population and health system levels.

In this study, hypertension accounts for the highest number of avoidable deaths (this risk factor is prioritized at the interventions). According to the result of STEPs survey performed in 2016, 54\% of people aged 30-70 years are aware of hypertension, of whom $37 \%$ receive treatments. Hypertension in $37 \%$ of these individuals, is under control ${ }^{9}$. Therefore, the main measures for reducing the hypertension, would be boosting awareness and having effective coverage of controlled hypertension. It is recommended to conduct national preparation program to identify and control hypertension and develop a set of self-care management strategies. Sensitization should be performed up to the extent that each person knows her own blood pressure number. Also, part of the avoidable deaths due to hypertension is due to the high level of salt intake. Given that about 70 percent of the salt is sodium and it is added to the food outside the home ${ }^{10}$, it is suggested that intersectoral collaboration interventions for modification in the processes of production of food industry be conducted to reduce salt intake. At the population level, mass media can be employed to change the consumer behaviors; also, launching some campaigns would be a plus in this regard. At the individual level, the "table without shaker" campaign can be an effective intervention.

After hypertension, the highest number of avoidable deaths is associated, respectively, with physical inactivity and obesity. To reduce avoidable deaths from physical inactivity, infrastructures must be provided at the macro level. Creating an appropriate and safe infrastructures to support hiking and cycling and providing social security to support individuals-especially women-who can have physical activity at free times, is necessary. To increase public awareness and motivate the community to avoid physical inactivity, the mass media can be a game-changer in terms of the behavior of individuals and groups. Sports programs can be designed to be performed in places such as parks, streets, schools and the workplaces. An example of this program is the ParticipACTION program proposed by the Canadian government to encourage the general population to increase physically activity and to achieve physical health. This program led to reduction in health costs ${ }^{11}$. One of the benefits of having physical activity is the balance of energy and the prevention of obesity ${ }^{12}$. Given the challenges in the implementation of individual interventions to reduce obesity, there is an emphasis on the population and intersectorial interventions. Apart from interventions designed for increasing physical activity level, it is suggested to educate public on nutrition and counsel them in different environments (such as schools, work environments, ...), use food labels to reduce overall energy consumption (traffic light) and diet reform, tax on sweet drinks and processed foods and Fast foods, and refine schools and mass media campaigns on healthy diets. Consultation on non-communicable Risk Factors can be included as part of the Primary Health Services (PHC) that will be plausible and cost-effective through the trained health care provider.

\section{Conclusions}

Given the current trends, Iran is unlikely to achieve SDG 3.4. Therefore, it is recommended thath the Ministry of Health, besides intersectorial collaboration with the other organizations, consider all life-style and pharmacological interventions at individual and population levels. It seems that inter-sectorial health system interventions can bring about clear solutions for public, health care community, policy makers, and insurance companies to achieve SDG 3.4 while there is still time to the end of SDGs deadline.

\section{Methods}

After addressing the incompleteness and misclassifications in the Iranian Death Registry System (DRS), it was employed to estimate the trends of UPoD for four major categories of NCDs (cancers, cardiovascular diseases, asthma and COPD, and diabetes). Deploying Bayesian Model Averaging (BMA) for UPoD in four major NCDs categories were projected at the national and sub-national levels by 2030 and the achievement chance to the SDG 3.4 was evaluated. In parallel with this, using BMA and Spatio-Temporal models, the prevalence of six major risk factors (Diabetes, Hypertension, Overweight and Obesity, Physical Inactivity, Cigarette Smoking, Salt Intake) were projected by 2030. Avoidable deaths from reducing NCDs risk factors were calculated using Population Attributable Fraction (PAF). UPoD was projected again after reducing avoidable deaths and then the extent of achieving SDG 3.4 at national and sub-national levels was studied in different scenarios. Gain in life expectancy after elimination of major NCDs causes of death was estimated by 2030 . Study flow was shown in flowchart 1 and 2.

\section{Definitions}

Unconditional probability of dying (UPOD): Unconditional probability of dying between ages 30 and 70 years (premature deaths) from NCDs.

Scenario 10: One third decrease in the UPoD compared to 2010, if current trend continued.

Scenario 15: One third decrease in the UPoD compared to 2015 if current trend continued

WHO based scenarios 10: One third decrease in the UPoD if the risk factors decreased to the recommended level by WHO compared to 2010. 
WHO based scenarios 15: One third decrease in the UPoD if the risk factors decreased to the recommended level by WHO compared to 2015.

\section{Data sources}

1. Death data

We used the Iranian death registration system (DRS). Misclassification and incompleteness of DRS were addressed using Death Distribution Methods to address incompleteness of DRS. This is discussed in more detail elsewhere ${ }^{13,14}$. Moreover, redistribution method was adopted to correct the misclassifications in the causes of death and the inconsistency of the causes with age and sex. Also, the deaths were recorded with many cases of duplicate data that were corrected. Over the course of time, Iran's administrative division was changed, resulted in an increase in the number of the provinces. Thus, the data was restructured for the new provinces ${ }^{15}$. To evaluate all-cause mortality rates the age-spatio-temporal, Gaussian Process Regression (GPR), and Generalized Linear Mixed Models were employed, The method is described in more detail elsewhere ${ }^{13,14}$.

Due to the modifications found in the registry code and data collection institution before and after 2001, the data before the year of 2001 was not used. The DRS for that period of time (before 2001) were not included data for the cities of Tehran and Isfahan. We used information from the cemeteries of Behest-e Zahra in Tehran and Bagh-e Rezvan in Isfahan to complete our datasets. Detailed description has been included elsewhere ${ }^{15}$.

\section{Prevalence of risk factors data}

The main sources for estimating the trend of prevalence of risk factors were STEPs Surveys carried out for seven rounds in Iran. These surveys were conducted in 2005 to 2009, 2011 and 2016. These surveys include large sample size and representative of the Iranian population. Plus, to estimate the prevalence of diabetes, hypertension and obesity and overweight, some additional studies were employed that had been conducted in Iran (table 1). The trend of mean of salt intake was obtained from STEPs 2016 and the other Iranian studies (table1).

\section{Relative Risk (RR)}

RRs were extracted from the Global Burden of Disease (GBD) and NCD.RisC (NCD risk factor collaboration) ${ }^{16-19}$. These RRs were derived for each risk factorsdisease pair. These RRs were categorized by age and sex.

\section{Population data}

The population data came from censuses carried out in 1996, 2006, 2011, and 2016, as well as the Iranian statistical yearbook by sex, age and province. Spectrum software (version 5.72) was employed to project population by 2030.

\section{Covariate data}

We used household expenditure and income survey to estimate the variables of the wealth index, years of schooling, and urbanization until 2015 sorted by age, sex, and province of residence ${ }^{20}$. Also, the spline method was used to estimate these covariates of wealth index, years of schooling, and urbanization until 2030. Then the results were entered into the covariate model.

\section{Statistical analysis}

\section{Unconditional Probability of Dying}

UPoD was calculated based on WHO guideline from 2001 to $2015^{21}$. Bayesian Model Averaging (BMA) was used for its projection by 2030 . In this model, we have ten covariates (six risk factors, wealth index, years of schooling, the percent of urbanization and population), $2^{10}=1024$ different models were the result. BMAs in all the models were integrated and based on the marginal likelihood of each model, they were weighted. In this model, prior distribution was assumed to be uniform. The number of burn-ins, and iterations were retained 5000 and 20000 , respectively. Choosing the baseline for comparison was optional. In this study, we considered 2010 and 2015 as the two baselines to conduct comparisons and project SDG 3.4 achievement status (scenario10, scenario15). The level of 2010 is the goal of WHO but the values for 2015 are more up to date.

\section{Risk factors}

The prevalence of diabetes, hypertension and obesity, and overweight was estimated with Gaussian Process Regression (GPR) to 2015, more details are available elsewhere 22,23 . The prevalence of Physical inactivity and smoking were extrapolate from 2001 to 2005 and missing points were interpolate in with spatiotemporal model. The data for two risk factors are available in 2000. We have not any data for 2001 to 2005 . The trend of prevalence of risk factors projected with BMA and spatiotemporal models (more details in supplementary appendix 1).

\section{Population Attributable Fraction (PAF)}

PAF was calculated for each pair of the risk factor-disease (supplementary appendix 2) in different scenarios for risk factors in the two baselines (2010 and 2015 baselin333e) by sex and province. Risk factor scenarios are presented in table 1. Joint effect of risk factors was calculated as well (Equation 1). Mortality rate was projected with spatio-temporal model by sex, cause and province in 2030 .

Equation 1 
$P A F=1-\prod_{i=1}^{n}\left(1-P A F_{i}\right)$

Then the number of deaths from the multiplication of the death rate in the population was achieved. After reducing the avoidable deaths from projected deaths, the UPoD was calculated again, therefore was checked achieve to the SDG 3.4.

\section{Cause Deleted Life Table}

The impact of reducing the causes of death from major NCDs on increasing life expectancy was estimated by cause deleted life table and the composition method by 2030 .

\section{Declarations}

\section{Acknowledgments}

This project has been granted by Kerman University of Medical Sciences. The authors would like to express their deep appreciation to Prof.Majid Ezzati, Dr.Vasilis Kontis and Non-Communicable Diseases Research Center (NCDRC) in Tehran University of Medical Sciences who contributed in conducting this study by providing useful data and valuable comments.

\section{Author Contributions}

F KHSH, AK H, and FF designed the study.

AK H, F F, and B L supervised the study.

F KHSH and M Y processed the data.

F KHSH, M Y, and K M, MR B, and did the statistical analysis.

$\mathrm{F} \mathrm{KHSH}, \mathrm{AK} \mathrm{H}, \mathrm{F} \mathrm{F}, \mathrm{K} \mathrm{M}$, and MR B interpreted the results.

F KHSH, AK H, F F, M Y, K M, MR B, and B L wrote the original draft.

F KHSH, AK H, F F, B L review and edit the final draft.

\section{Competing interests}

The author(s) declare no competing interests.

\section{Funding}

Kerman University of Medical Sciences (Iran)

\section{References}

United Nations. Sustainable Development Goals 2015, < https://www.un.org/sustainabledevelopment/sustainable-development-goals/> (

2 World Health Organization. NCD Global Monitoring Framework 2011

3 Institute for Health Metrics and Evalution. GBD Compare. Seattle, WA: IHME, University of Washington; 2015.

4 Abegunde, D. O., Mathers, C. D., Adam, T., Ortegon, M. \& Strong, K. The burden and costs of chronic diseases in low-income and middle-income countries. The Lancet 370, 1929-1938 (2007).

5 Khosravi Shadmani, F., Farzadfar, F., Larijani, B., Mirzaei, M. \& Haghdoost, A. A. Trend and projection of mortality rate due to non-communicable diseases in Iran: A modeling study. PloS one 14 (2019).

6 Bennett, J. E. et al. NCD Countdown 2030: worldwide trends in non-communicable disease mortality and progress towards Sustainable Development Goal target 3.4. The Lancet 392, 1072-1088 (2018).

7 González-Pier, E. et al. Mexico's path towards the Sustainable Development Goal for health: an assessment of the feasibility of reducing premature mortality by $40 \%$ by 2030 . The Lancet Global Health 4, e714-e725 (2016).

$8 \mathrm{Li}$, Y. et al. Can China achieve a one-third reduction in premature mortality from non-communicable diseases by 2030 ? BMC medicine 15, 132 (2017)

9 VISIT. Data Visualization System: Non-Communicable Diseases Research Center 2019.

Harnack, L. J. et al. Sources of sodium in US adults from 3 geographic regions. Circulation 135, 1775-1783 (2017). 
Barnes, J. D. et al. Results from Canada's 2016 ParticipACTION report card on physical activity for children and youth. Journal of physical activity and health 13, S110-S116 (2016).

12 Committee on Accelerating Progress in Obesity Prevention. Accelerating progress in obesity prevention: solving the weight of the nation. (National Academies Press, 2012).

13 Mohammadi, Y. et al. Levels and trends of child and adult mortality rates in the Islamic Republic of Iran, 1990-2013; protocol of the NASBOD study. (2014).

14 Parsaeian, M. et al. APPLICATION OF SPATIO-TEMPORAL MODEL TO ESTIMATE BURDEN OF DISEASES, INJURIES AND RISK FACTORS IN IRAN 1990-2013 (STUDY PROTOCOL). (2014).

15 Gohari, K., Rezaei, N. \& Farshad Farzadfar, M. National and subnational patterns of cause of death in Iran 1990-2015: Applied methods. Archives of Iranian medicine 20, 2 (2017).

16 Kontis, V. et al. Contribution of six risk factors to achieving the $25 \times 25$ non-communicable disease mortality reduction target: a modelling study. The Lancet 384, 427-437 (2014).

17 Gakidou, E. et al. Global, regional, and national comparative risk assessment of 84 behavioural, environmental and occupational, and metabolic risks or clusters of risks, 1990-2016: a systematic analysis for the Global Burden of Disease Study 2016. The Lancet 390, 1345-1422 (2017).

18 Forouzanfar, M. H. et al. Global, regional, and national comparative risk assessment of 79 behavioural, environmental and occupational, and metabolic risks or clusters of risks, 1990-2015: a systematic analysis for the Global Burden of Disease Study 2015. The lancet 388, 1659-1724 (2016).

19 Kontis, V. et al. Regional contributions of six preventable risk factors to achieving the $25 \times 25$ non-communicable disease mortality reduction target: a modelling study. The Lancet Global Health 3, e746-e757 (2015).

20 Kasaeian, A. et al. BAYESIAN AUTOREGRESSIVE MULTILEVEL MODELING OF BURDEN OF DISEASES, INJURIES AND RISK FACTORS IN IRAN $1990-$ 2013 (STUDY PROTOCOL). (2014).

21 World Health Organization. Noncommunicable Diseases Global Monitoring Framework: Indicator Definitions and Specifications. 2014b.

22 Khosravi Shadmani, F. National and subnational levels achievement to Sustainable Development Goals (SDGs) for non-communicable diseases in Iran: modeling study with scenario-based projection, School of Health, Kerman University of Medical Sciences, Kerman, Iran, (2019).

Mehdipour, P. \& Ghanbari, M. A. Package ‘GPRMortality’. (2018).

\section{Tables}


Table 1. All characteristics of risk factors, WHO targets and theoretical minimum risk exposure level

Risk factor $\begin{aligned} & \text { Exposure } \\ & \text { definition }\end{aligned} \quad$ Data source $\quad$ Related disease

\begin{tabular}{ll}
$\begin{array}{l}\text { WHO } \\
\text { target for } \\
\text { risk } \\
\text { factors }\end{array}$ & $\begin{array}{l}\text { Theoretica } \\
\text { minimum } \\
\text { risk } \\
\text { exposure } \\
\text { level } \\
\text { (TMREL) }\end{array}$ \\
\hline $\begin{array}{l}25 \% \\
\text { relative } \\
\text { reduction } \\
\text { in the } \\
\text { prevalence } \\
\text { of raised } \\
\text { blood } \\
\text { pressure }\end{array}$ & $\begin{array}{l}110-115 \\
\text { mm Hg }\end{array}$ \\
\hline
\end{tabular}

\begin{tabular}{|c|c|c|}
\hline $\begin{array}{l}\text { High } \\
\text { Systolic } \\
\text { and }\end{array}$ & $\begin{array}{l}\text { Mean of } \\
\text { systolic and } \\
\text { diastolic }\end{array}$ & $\begin{array}{l}\text { STEPs surveys ( from } \\
2005 \text { to } 2009-2011-2016 \text { ) }\end{array}$ \\
\hline $\begin{array}{l}\text { diastolic } \\
\text { blood } \\
\text { pressure }\end{array}$ & $\begin{array}{l}\text { blood } \\
\text { pressure, } \\
\text { measured in } \\
\mathrm{mmHg}\end{array}$ & $\begin{array}{l}\text { An additional studies: } \\
\text { GCS }^{1}, \text { IHHP }^{2}, \text { MONICA }^{3} \text {, } \\
\mathrm{NHS}^{4}, \mathrm{TLGS}^{5}\end{array}$ \\
\hline
\end{tabular}

Rheumatic heart disease, Hypertensive heart disease, Ischemic heart disease, Ischemic stroke, Hemorrhagic and other nonischemic stroke, Cardiomyopathy, myocarditis, endocarditis, Atrial fibrillation and flutter, Other circulatory diseases, Chronic obstructive pulmonary disease, Kidney Disease

pressure

\begin{tabular}{|c|c|c|c|c|c|}
\hline \multirow[t]{2}{*}{ High FPG } & \multirow{2}{*}{$\begin{array}{l}\text { Mean of } \\
\text { serum } \\
\text { fasting } \\
\text { plasma } \\
\text { glucose } \\
\text { measured in } \\
\mathrm{mg} / \mathrm{dl}\end{array}$} & $\begin{array}{l}\text { STEPs surveys (from } \\
2005 \text { to } 2009-2011-2016 \text { ) }\end{array}$ & \multirow[t]{2}{*}{$\begin{array}{l}\text { Diabetes mellitus, Ischemic heart disease, Ischemic stroke, } \\
\text { Hemorrhagic and other non-ischemic stroke, Kidney disease }\end{array}$} & \multirow{2}{*}{$\begin{array}{l}\text { Halt the } \\
\text { rise in } \\
\text { diabetes }\end{array}$} & \multirow[t]{2}{*}{$\begin{array}{l}4 \cdot 8-5 \cdot 4 \\
\mathrm{mmol} / \mathrm{L}\end{array}$} \\
\hline & & $\begin{array}{l}\text { An additional studies: } \\
\text { GCS, IHHP, MONICA, } \\
\text { NHS,TLGS }\end{array}$ & & & \\
\hline
\end{tabular}

\begin{tabular}{|c|c|c|c|c|c|}
\hline \multirow[t]{2}{*}{$\begin{array}{l}\text { Obesity } \\
\text { and } \\
\text { overweight }\end{array}$} & \multirow{2}{*}{$\begin{array}{l}\text { Mean of } \\
\text { body mass } \\
\text { index, } \\
\text { measured in } \\
\mathrm{kg} / \mathrm{m}^{2}\end{array}$} & $\begin{array}{l}\text { STEPs surveys (from } \\
2005 \text { to } 2009-2011-2016 \text { ) }\end{array}$ & \multirow{2}{*}{$\begin{array}{l}\text { Colon and rectum cancers, Liver cancer, Pancreas cancer, Breast } \\
\text { cancer, Corpus uteri cancer, Ovary cancer, Prostate cancer, Non- } \\
\text { Hodgkin lymphoma, Other lymphomas and multiple myeloma, } \\
\text { Leukemia, Kidney cancer, Gallbladder cancer, Thyroid cancer, } \\
\text { Diabetes mellitus, Hypertensive heart disease, Ischemic heart } \\
\text { disease, Ischemic stroke, Hemorrhagic and other non-ischemic } \\
\text { stroke, Kidney disease }\end{array}$} & \multirow[t]{2}{*}{$\begin{array}{l}\text { Halt the } \\
\text { rise in } \\
\text { obesity }\end{array}$} & \multirow[t]{2}{*}{$\begin{array}{l}21-25 \\
\mathrm{~kg} / \mathrm{m}^{2}\end{array}$} \\
\hline & & $\begin{array}{l}\text { An additional studies: An } \\
\text { additional studies: GCS, } \\
\text { IHHP, MONICA, NHS,TLGS }\end{array}$ & & & \\
\hline $\begin{array}{l}\text { Physical } \\
\text { inactivity }\end{array}$ & $\begin{array}{l}\text { Average } \\
\text { weekly } \\
\text { physical } \\
\text { activity at } \\
\text { work, home, } \\
\text { transport- } \\
\text { related, and } \\
\text { recreational }\end{array}$ & $\begin{array}{l}\text { STEPs surveys ( from } \\
2005 \text { to } 2009-2011-2016 \text { ) }\end{array}$ & $\begin{array}{l}\text { Colon and rectum cancers, Breast cancer, Diabetes mellitus, } \\
\text { Ischemic heart disease, } \\
\text { Ischemic stroke }\end{array}$ & $\begin{array}{l}10 \% \\
\text { reduction } \\
\text { in the } \\
\text { prevalence } \\
\text { of } \\
\text { physical } \\
\text { inactivity }\end{array}$ & $\begin{array}{l}\text { All adults } \\
\text { experience } \\
3000- \\
4500 \mathrm{MET} \\
\text { min per } \\
\text { week }\end{array}$ \\
\hline
\end{tabular}

$\begin{array}{ll}\text { Smoking } & \begin{array}{l}\text { Daily } \\ \text { smoking }\end{array} \\ & \\ & \begin{array}{l}\text { Smoking } \\ \text { Impact } \\ \text { ratio(SIR) }\end{array}\end{array}$

STEPs surveys ( from
2005 to $2009-2011-2016)$

Mouth and oropharynx cancers, Esophagus cancer, Stomach cancer, Colon and rectum cancers, Liver cancer, Pancreas cancer

Trachea, bronchus and lung cancers, Melanoma and other skin cancers, Breast cancer, Cervix uteri cancer, Corpus uteri cancer, Ovary cancer, Prostate cancer, Bladder cancer, Non-Hodgkin lymphoma, Multiple myeloma, Other lymphomas and multiple myeloma, Leukemia, Kidney cancer, Gallbladder cancer, Thyroid cancer, Diabetes mellitus, Rheumatic heart disease, Hypertensive heart disease, Ischemic heart disease, Ischemic stroke, Hemorrhagic and other non-ischemic stroke, Chronic obstructive, pulmonary disease, Asthma, Other respiratory diseases

$\begin{array}{ll}30 \% & \text { All } \\ \text { relative } & \text { individuals } \\ \text { reduction } & \text { are lifelong } \\ \text { in the } & \text { non- } \\ \text { prevalence } & \text { smokers } \\ \text { of current } & \\ \text { tobacco } & \\ \text { use } & \end{array}$

Direct : Stomach cancer

Indirect : Rheumatic heart disease, Hypertensive heart disease Ischemic heart disease, Ischemic stroke, Hemorrhagic and other non-ischemic stroke, Cardiomyopathy, myocarditis, endocarditis, Atrial fibrillation and flutter, Other circulatory diseases, Chronic obstructive pulmonary disease, Kidney Disease

$\begin{array}{ll}30 \% & 24 \mathrm{~h} \\ \text { reduction } & \text { urinary } \\ \text { in the } & \text { sodium } \\ \text { mean } & \text { between } 1 \\ \text { population } & \text { g and } 5 \mathrm{~g} \\ \text { intake of } & \text { per day } \\ \text { salt } & \end{array}$

Study, YHHP ${ }^{7}$, Urban

Health Equity assessment and Response Tool

(Urban Heart-phase1)

$\mathrm{HIES}^{8}$

\section{Golestan Cohort Study}

2. Isfahan Healthy Heart Program

3. Monitoring trends and determinants in cardiovascular disease

4. National Health Survey 
5. The Tehran Lipid and Glucose Study

6. Persian Gulf Healthy Heart Study

7. Yazd Healthy Heart Program

8. Household Income and Expenditure survey

Table 2. Prevalence of risk factors and mean of salt intake in three time periods by sex

\begin{tabular}{|c|c|c|c|c|c|c|}
\hline \multirow[t]{2}{*}{ Risk factor } & \multicolumn{2}{|l|}{2010} & \multicolumn{2}{|l|}{2015} & \multicolumn{2}{|l|}{ Projected by 2030} \\
\hline & $\mathbf{F}$ & $M$ & $\mathbf{F}$ & $M$ & $\mathbf{F}$ & M \\
\hline Diabetes (\%) & $8.9(8.4-9.3)$ & $7.3(6.9-7.8)$ & $9.5(9-9.9)$ & $7.9(7.5-8.4)$ & $11.2(10.8-11.7)$ & $9.5(9.0-10.0)$ \\
\hline Hypertension (\%) & $25.4(23.2-27.5)$ & $21.0(19.3-22.7)$ & $30.0(27.9-32.1)$ & $24.8(23.1-26.4)$ & $42.5(39.0-46.1)$ & $35.2(32.1-38.5)$ \\
\hline Obesity (\%) & $\begin{array}{l}27.3(25.0- \\
29.6)\end{array}$ & $14.3(12.9-15.8)$ & $\begin{array}{l}32.2(30.1- \\
34.1)\end{array}$ & $17.7(16.3-19.1)$ & $42.6(40.2-45.2)$ & $26.3(23.8-28.9)$ \\
\hline Physical inactivity (\%) & $50.4(46.4-54.2)$ & $\begin{array}{l}38.5(34.5- \\
42.3)\end{array}$ & $\begin{array}{l}58.6(55.1- \\
61.9)\end{array}$ & $46.8(43.1-50.2)$ & 75.9(71.9-79.9) & $65.5(61.1-70.2)$ \\
\hline Smoking (\%) & $3.7(3.7-3.7)$ & $\begin{array}{l}27.1(25.2- \\
29.0)\end{array}$ & $3.3(3.3-3.3)$ & $24.3(22.4-26.3)$ & $2.4(2.4-2.4)$ & $17.6(15.6-19.5)$ \\
\hline $\begin{array}{l}\text { Mean of Salt intake (grams per } \\
\text { day) }\end{array}$ & $9.6=-(9.5-9.8)$ & $\begin{array}{l}10.4(10.2- \\
10.6)\end{array}$ & $9.3(9.1-9.5)$ & $9.9(9.7-10.1)$ & $8.2(7.6-8.8)$ & $8.3(7.7-8.9)$ \\
\hline
\end{tabular}

Table 3. Avoidable deaths by NCDs categories with reducing the risk factors by 2030

\begin{tabular}{|c|c|c|c|c|c|c|c|c|c|c|c|c|c|c|c|c|c|}
\hline \multirow[t]{3}{*}{ Risk factor } & \multicolumn{8}{|c|}{ Theoretical minim exposure risk level scenario * } & \multicolumn{8}{|c|}{ WHO-based scenario 10 ‡ } & \multirow{3}{*}{$\begin{array}{l}\text { WHO-t } \\
\text { Cance } \\
\text { F }\end{array}$} \\
\hline & \multicolumn{2}{|c|}{ Cancers } & \multicolumn{2}{|l|}{ CVDs } & \multicolumn{2}{|c|}{$\begin{array}{l}\text { Asthma \& } \\
\text { COPD }\end{array}$} & \multicolumn{2}{|c|}{ Diabetes } & \multicolumn{2}{|c|}{ Cancers } & \multicolumn{2}{|l|}{ CVDs } & \multicolumn{2}{|c|}{$\begin{array}{l}\text { Asthma \& } \\
\text { COPD }\end{array}$} & \multicolumn{2}{|c|}{ Diabetes } & \\
\hline & $F$ & M & $\mathbf{F}$ & M & $\mathbf{F}$ & M & $\mathbf{F}$ & M & $F$ & M & $\mathbf{F}$ & M & $\mathbf{F}$ & M & F & M & \\
\hline Diabetes & - & - & 10443 & 18611 & - & - & 2455 & 2286 & - & - & 473 & 1159 & - & - & 1044 & 884 & - \\
\hline Hypertension & - & $\begin{array}{l}- \\
\text { scenario } \\
1\end{array}$ & 27798 & 26026 & - & - & 95 & 91 & - & - & 9342 & 9746 & - & - & 35 & 24 & - \\
\hline Obesity & 1949 & 1004 & 7622 & 9550 & - & - & 1964 & 1526 & 752 & 438 & 2085 & 3185 & - & - & 451 & 495 & 277 \\
\hline $\begin{array}{l}\text { Physical } \\
\text { inactivity }\end{array}$ & 1089 & 832 & 1003 & 326 & - & - & 4545 & 7151 & 798 & 365 & 3591 & 7943 & - & - & 866 & 931 & 606 \\
\hline Smoking & 1649 & 757 & 7435 & 4482 & 678 & 385 & 180 & 53 & 158 & 322 & 918 & 1521 & 77 & 135 & 12 & 40 & 173 \\
\hline $\begin{array}{l}\text { Mean of Salt } \\
\text { intake }\end{array}$ & 334 & 594 & 10947 & 17961 & - & - & - & - & 83 & 151 & 6267 & 8566 & - & - & - & - & 117 \\
\hline
\end{tabular}

* Avoidable deaths happen by each risk factor to the theoretical minim exposure risk level

‡ WHO-based scenario10: Avoidable deaths happen by reduce each risk factor to WHO recommended level compared 2010

$\Psi$ WHO-based scenario15: Avoidable deaths happen by reduce each risk factor to WHO recommended level compared 2015 
Table 4. Gain in life expectancy after elimination of major causes of death from NCDs

\begin{tabular}{|c|c|c|c|c|c|}
\hline & Gender & Life expe & tancy & & \\
\hline \multirow[t]{2}{*}{ life expectancy in 30-70 age group by 2015} & Female & 39.62 & & & \\
\hline & Male & 36.30 & & & \\
\hline \multirow[t]{3}{*}{ life expectancy in $30-70$ age group by 2030 (projected) } & Female & 45.46 & & & \\
\hline & Male & 40.63 & & & \\
\hline & & Cancers & CVDs & Asthma and COPD & Diabetes \\
\hline \multirow[t]{2}{*}{ Gains in life expectancy after elimination in WHO based scenario10 } & Female & 0.18007 & 1.70329 & 0.00273 & 0.05972 \\
\hline & Male & 0.17576 & 2.40042 & 0.00515 & 0.06189 \\
\hline \multirow[t]{2}{*}{ Gains in life expectancy after elimination in WHO based scenario15 } & Female & 0.15068 & 1.18563 & 0.00245 & 0.03735 \\
\hline & Male & 0.13693 & 1.47734 & 0.00466 & 0.03437 \\
\hline
\end{tabular}

\section{Figures}

a

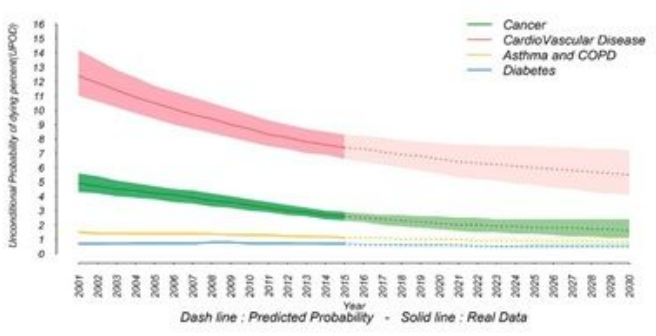

b

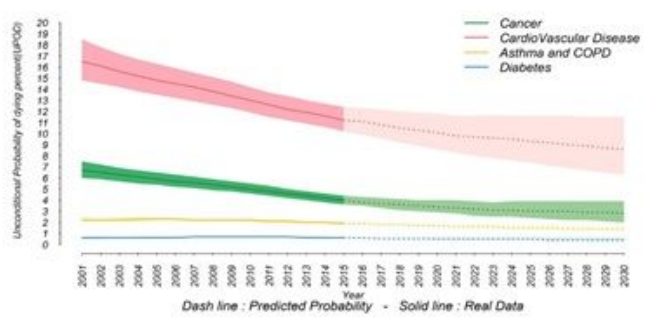

Figure 1

Trends and projections of unconditional probability of dying in four categories of NCDs. a) Females, b) Males 

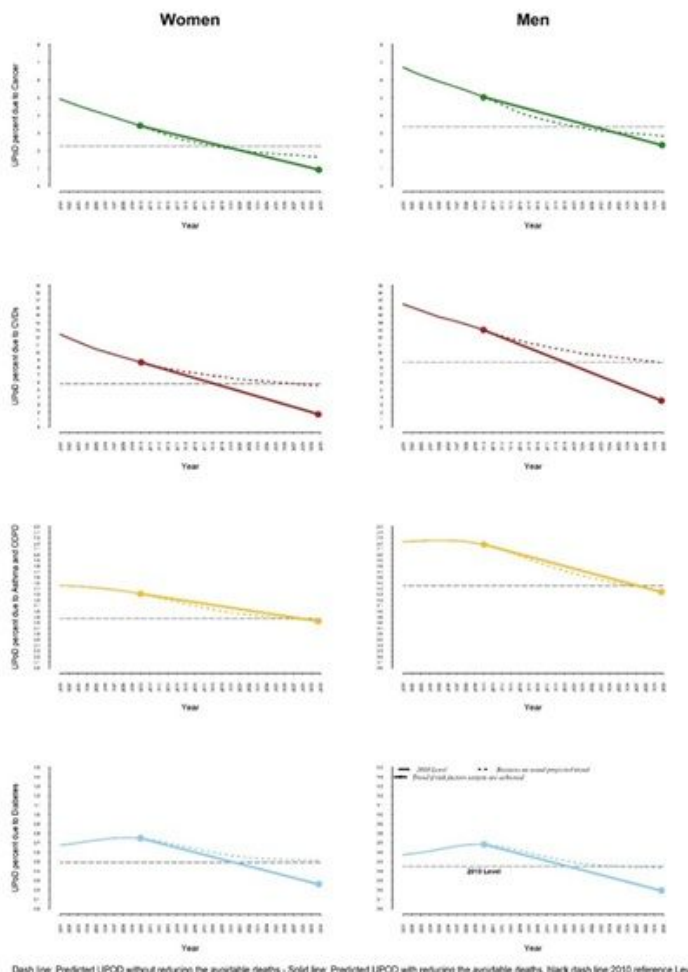

Figure 2

Comparing the projected UPoD (if the current trend goes on) with the UPoD after reducing the avoidable deaths in WHO-based scenario10
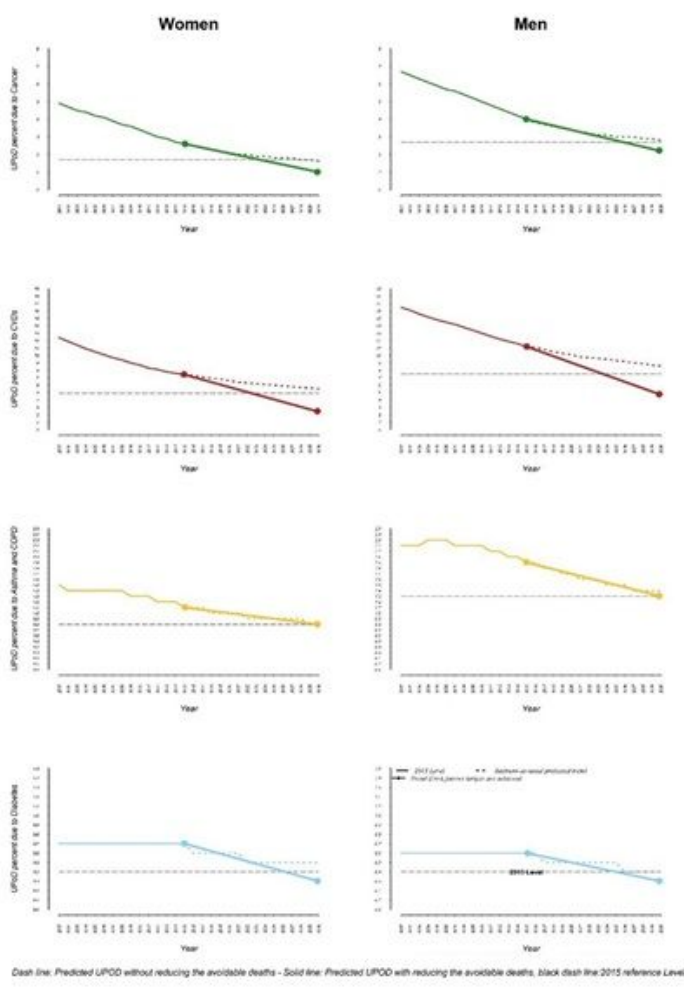

\section{Figure 3}

Comparing the projected UPoD (if the current trend goes on) with the UPoD after reducing the avoidable deaths in WHO-based scenario15 


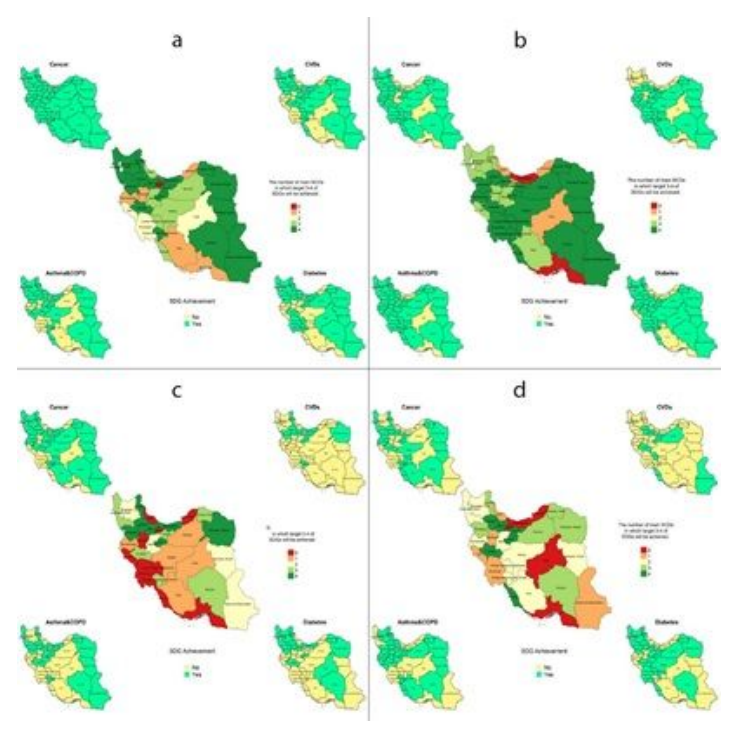

Figure 4

Achieving SDG 3.4 in current situation in the 2 scenarios. a) Female in scenario10, b) Male in scenario10, c) Female in scenario15, d) Male in scenario15.

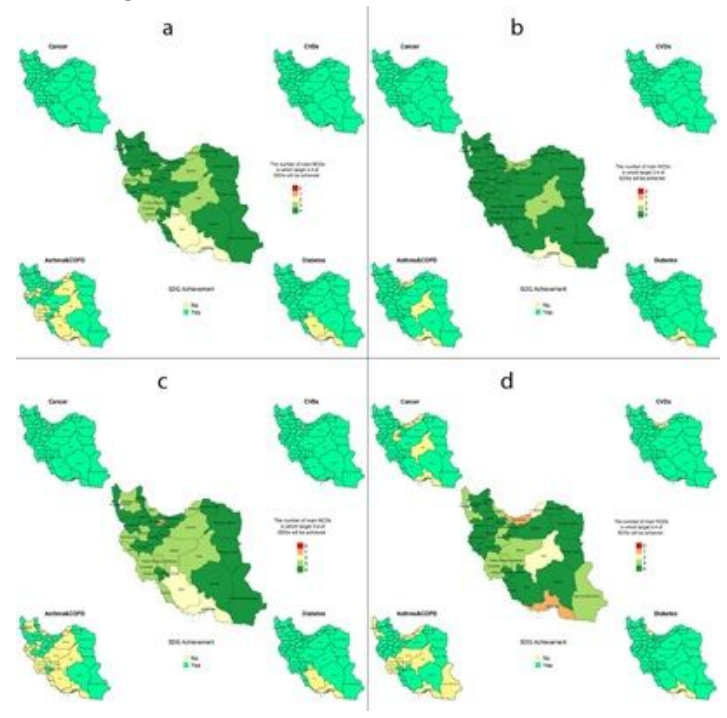

Figure 5

Achieving SDG 3.4 in WHO based scenario in the 2 scenarios. a) Female in WHO based scenario10 , b) Male in WHO based scenario10 , c) Female in WHO based scenario15, d) Male in WHO based scenario15.

\section{Supplementary Files}

This is a list of supplementary files associated with this preprint. Click to download.

- Supplementary.docx

- Flowcharts.pdf 